\title{
Implementing Strategic Orientation
}

Arthur K. Fischer, Pittsburg State University, USA

Sarah Brownback, Pittsburg State University, USA

\begin{abstract}
An HRM case dealing with problems and issues of setting up orientation programs which align with corporate strategy. Discussion concerns how such a case can be used to exhibit the alignment between HRM and business strategy.
\end{abstract}

Keywords: HRM Case; Orientation; Strategy

\section{INTRODUCTION}

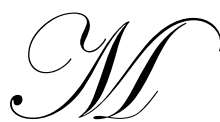

idwest Education, Inc. is a major supplier of educational materials for the United States. The company focus is on learning tools and systems for use in technology, science and business classrooms. In addition, it develops and provides books, manuals, videos, software and hardware used in the fields of technology education, instructional development and business applications.

The company has its headquarters and primary manufacturing plant in a major Midwest community. In addition, the Creative Development offices are located in Massachusetts and California. Transportation, Service and Maintenance facilities are headquartered out of Texas, with major branches in Baltimore and Phoenix.

The three main divisions exemplify three different strategies: cost-reduction, quality enhancement, and innovation (as discussed by Schuler and Jackson, 1987).

Transportation, Service and Maintenance. The primary strategy of the Transportation, Service and Maintenance Division is cost-reduction. Midwest Education, Inc. has long been known for providing service and maintenance programs which are very reasonably priced.

Manufacturing. The primary strategy of the Manufacturing Division is quality enhancement. Midwest education, Inc. has an enviable history of providing the highest quality products which have been adopted by first-rate schools and corporate training programs.

Creative Development. The primary strategy of the Creative Development Division is innovation. Midwest Education, Inc. is widely known for providing truly cutting edge teaching materials which always mirror the latest techniques and processes.

Various HRM problems occur at these different facilities. These problems require students to develop responses and show how their responses can support the overall strategic plans of the division involved.

\section{COMPANY HISTORY}

Midwest Education was started by Henry and Mary Dalton in 1975. Dr. Henry Dalton was an industrial arts teacher before he got his MBA and went on to get his Ph.D. in Technology Education. Mary was a software developer who also taught business seminars. At that time a new wave of emerging technology was beginning to alter the way people learn and communicate. By developing Midwest Education, Inc. the Daltons began work in an exciting new field. They found a vast market for quality tools that educated people on how to use all the new technology. Dr. and Mrs. Dalton are in semi-retirement now and travel extensively, but remain major shareholders in the business. They personally hired the CEO when they went into semi-retirement. 
The company started with about fifty employees, but has grown consistently and now has a total of 416 employees within its three major divisions: 158 employees work in the Manufacturing Division, 123 work in the Creative Development Division and 135 work in the Transportation, Service and Maintenance Division. There are also 71 employees working at the headquarters in Kansas City (including the corporate staff).

At the beginning on the 1990s it became apparent that international business was becoming the rule rather than the exception. The company went international in 1994 and now is exporting to three European, two Latin American, and two Pacific Rim countries. The Global Operations Division is located within the headquarters.

\section{HEADQUARTERS}

The corporate headquarters are in Kansas City. The CEO of Midwest Education, Inc. is Judith Lund. Ms Lund was hired by the Daltons in 1994 when they decided to take a less active role in the company while remaining major shareholders. Ms. Lund has an MBA in business management, and was previously the CEO of a small telecommunications company. In her previous position, Ms Lund had successfully steered the company out of financial difficulties by raising stock value. She had initiated a strong advertising campaign and had put the company 'in the black' for the first time in seven years.

The COO of Midwest Education, Inc. is Frank Rose. Frank has been with the company since 1989. Mr. Rose, a cousin of Dr. Dalton, had a successful career with an international business training group in California. His desire to move back to his home town of Kansas City came at a time when the Daltons were looking for a COO. He has worked out well for the company.

The Human Resources Department is also located at the headquarters. The Vice President for Human Resources is Lawrence Wilson. Mr. Wilson has a degree in industrial and organizational psychology and an MBA. He has been with the company for 11 years. He started out as a generalist and was promoted as he showed good judgment with hiring and earned his MBA at the same time.

Within the Human Resources Department there are four sections:

1. Staffing, the head of this section is Patrick Shew.

2. Compensation and benefits section, headed by Michael Martin.

3. Labor management relations section, headed by Keith Lane.

4. Training, career development and performance appraisal section, headed by Cynthia Burns.

There are also human resource specialists in each of the three divisions around the country.

\section{MANUFACTURING DIVISION}

The mission statement for the Manufacturing Division is:

"The aim of the Manufacturing Division of Midwest Education, Inc. is to continually improve the quality and strength of all our products. The superior products for which we have become world renowned will still be manufactured along with new and innovative products and ideas. We will work hard to keep quality high and cost down while supplying customers with the best possible products in the shortest possible time." The Manufacturing Division follows a strategy of quality enhancement.

The main manufacturing plant is located on the outskirts of Kansas City, not far from the company headquarters. The president of the Manufacturing Division is Max Thorn. Mr. Thorn has been with the company almost since its inception. He was one of the first employees hired by the Daltons. He started writing programs for the company and originally worked alongside the Daltons in interviewing and hiring many other employees.

The head of human resources for the Manufacturing Division is Janine Woods. She has a staff of five generalists who assist her in meeting HRM needs for the Manufacturing Division. 
The Manufacturing Division used to be housed in the same building as the headquarters. As the business expanded and more room was needed, the division moved to the suburbs into a large factory site. There are 158 employees in the Manufacturing Division. They are divided into ten teams, each team works at producing and packaging a specific product at a time. There are five supervisors who each supervise two teams: Doris Malone, John Fizer, Sandi Cross, Wendy Atchison, and Ian Carpenter.

The Manufacturing Division usually has a long lead time on orders and can anticipate what will be needed. The factory has flexible work areas that can be re-tooled and rearranged for the changeover from one product to another in less than four hours. The pay in this Division starts at $\$ 6.25 / \mathrm{hr}$ for production workers and has a full benefits package. Most employees seem happy with their work. Max Thorn is generally thought of as a good, easy-going man to work for.

\section{CREATIVE DEVELOPMENT DIVISION}

The mission statement for the Creative Development Division is:

"In the Creative Development Division of Midwest Education, Inc. we will strive to bring our customers the most innovative and cutting edge programs and products in the world. Our team of creative professionals is constantly working to improve, upgrade, and create the most useful products to bring to our customers." This division follows a strategy of innovation.

The Creative Development Division has two locations; a headquarters in California and a branch located in Massachusetts. The president of the Creative Development Division is Serena Tibaldo. Ms. Tibaldo recently joined the company. Previously she was a software developer for a large computer game producer. She has a bachelor's degree in business and a computer programming master's degree, and is doing very well at Midwest.

The head of human resources for the Creative Development Division is Amelia Chi, who is located at the California headquarters. Ms. Chi has a staff of five assistants. The head of the human resource section at the Massachusetts branch is Virginia Fox. Ms Fox has a staff of two assistants.

There are 90 people employed at the California plant and 38 at the Massachusetts location. The California location opened in 1980 and the Massachusetts branch was opened in 1993. In the 1970's and 1980's many computer software programmers moved to the west coast to be located in Silicon Valley. Most people hired by Midwest Education, Inc. transferred from wherever they lived to the California branch, with the company paying all relocation expenses. By 1990 some employees desired to live in the east. The Daltons decided it was time to expand the company and in doing so decided the next branch would be in the Massachusetts area. Most of the long time elected to remain California. The majority of recent hires are in Massachusetts.

\section{TRANSPORTATION, SERVICE AND MAINTENANCE DIVISION}

The mission statement for the Transportation, Service and Maintenance Division is:

"The Transportation, Service, and Maintenance Division is committed to providing the fastest and most cost effective way of safely shipping our product to our customers. No effort will be spared as we streamline and improve our fast and friendly service". The Transportation, Service and Maintenance Division follows a strategy of cost-reduction.

The Transportation, Service and Maintenance Division headquarters is located in San Antonio, Texas. There are major branches in Baltimore, Maryland and Phoenix, Arizona. The President of the Transportation, Service and Maintenance Division is Mark Derrick. Mr. Derrick is based in San Antonio. Mr. Derrick has been with Midwest Education, Inc. for 13 years. He personally hires the managers for the other branches in Maryland and Arizona. 
The head of human resources for the Transportation, Service and Maintenance Division is Salvador Vasquez. Mr. Vasquez has a staff of five assistants. Mr. Vasquez appoints HR heads to the other branches. Often they are employees from San Antonio that he knows well and trusts.

The Transportation, Service and Maintenance Division was originally based in Kansas City. As the company grew a decision was made to relocate the division to Texas. The other branches are newer, with Maryland opening in 1989 and Arizona in 1996. There are 55 employees in San Antonio, and 40 in each of the other two branches.

\section{SITUATION}

Midwest Education, Inc. has been having issues in new employee productivity in all three divisions. Amelia Chi asked new employees to fill out a survey after their first month of employment. The most common complaint concerned the lack of an orientation program in order to raise productivity levels among new employees. The new employees felt that they were not properly prepared to begin tasks. Of the 25 new employees surveyed, 95\% felt that they did not have sufficient knowledge of how to complete tasks and what is expected of them before they were required to start working. Ms. Chi, the head of the human resource department for the Creative Development Division has suggested implementing an official orientation program.

Ms. Chi sent her suggestions to Judith Lund, the CEO of Midwest Education. Ms. Lund reviewed the information, and then requested the head of human resources for the Manufacturing Division and the Transportation, Service, and Maintenance Division to implement the same survey for new employees. The results of the survey were similar to the results at the Creative Development Division. The average percentage of employees that expressed concern over the lack of an orientation program was $93 \%$. After viewing the results of the survey and noting the success of several companies after enacting an orientation program, Midwest Education has decided to implement a new hire orientation program.

The first year with the orientation program will act as a trial run. Whether the orientation program will be implemented for the following years and budget for the program will be based solely on the results of the tests evaluating the success of the programs. The budget for the orientation program is $\$ 30,000$ to be divided between the three divisions. Ms. Lund has stipulated that the orientation program for each division must include at least 5 days of job shadowing.

There have been many activities considered for the orientation program. The activities deemed acceptable for the Midwest Education orientation program fall under the following categories: seminars and workshops, training videos, games and cases, information packets, and training camp.

For the seminars, a speaker travels to the headquarters of the division. The company pays the program fee, travel, and lodging expenses for the speaker. The travel expense total $\$ 700$ per seminar. Hotel accommodations cost $\$ 80$ per night.

\begin{tabular}{|l|c|c|c|}
\hline \multicolumn{1}{|c|}{ Seminar Topic } & Cost & Length & 1 Day Workshop \\
\hline Teamwork & $\$ 300 /$ day & 1 day & $\$ 300$ \\
\hline Computer Skills & $\$ 350 /$ day & 3 days & $\$ 350$ \\
\hline Cost Cutting & $\$ 300 /$ day & 2 days & $\$ 300$ \\
\hline Quality Management & $\$ 350 /$ day & 3 days & $\$ 350$ \\
\hline Creative Solutions & $\$ 400 /$ day & 2 days & $\$ 400$ \\
\hline
\end{tabular}

The training videos can be bought and shared among the divisions. Each training video takes half a day to view. 


\begin{tabular}{|l|c|}
\hline \multicolumn{1}{|c|}{ Training Videos } & Cost \\
\hline Teamwork & $\$ 800$ \\
\hline Creative Solutions & $\$ 950$ \\
\hline Quality Management & $\$ 800$ \\
\hline Diversity in Employment & $\$ 750$ \\
\hline How to be an Efficient Employee & $\$ 975$ \\
\hline Thinking Outside the Box & $\$ 1000$ \\
\hline How to Reduce Costs & $\$ 575$ \\
\hline
\end{tabular}

The games and cases come in a packet of 5 games and 5 cases and can be shared among the divisions. Each packet requires one day to complete.

\begin{tabular}{|l|l|}
\hline \multicolumn{1}{|c|}{ Games and Cases } & Cost \\
\hline Teamwork & $\$ 250$ \\
\hline Creative Solutions & $\$ 300$ \\
\hline Diversity in Employment & $\$ 275$ \\
\hline Reducing Costs & $\$ 250$ \\
\hline Thinking Outside the Box & $\$ 325$ \\
\hline
\end{tabular}

Information packets can be shared among the divisions. Each info packet requires the employee to read the packet on their own time.

\begin{tabular}{|l|l|}
\hline \multicolumn{1}{|c|}{ Information Packets } & Cost \\
\hline Creativity & $\$ 500$ \\
\hline Quality & $\$ 450$ \\
\hline Cost Cutting & $\$ 475$ \\
\hline
\end{tabular}

Camp accommodates all new employees and includes travel expenses and hotel accommodations.

\begin{tabular}{|l|l|l|}
\hline \multicolumn{1}{|c|}{ Camp } & Cost & \multicolumn{1}{c|}{ Description } \\
\hline Creativity Package & $\$ 15,000$ & 1 week program encourages creativity \\
\hline Quality Package & $\$ 12,500$ & 1 week program teaches quality management \\
\hline Cost Cutting Package & $\$ 12,000$ & 1 week program teaches cost cutting activities \\
\hline
\end{tabular}

\section{Questions}

What activities should be included in the orientation program for each division?

How long should the orientation program be for each division?

How many days of job shadowing should each new hire undergo as part of the orientation program?

What other activities could Midwest Education include in the orientation program?

What type of evaluation should Midwest Education implement to measure the effectiveness of the orientation program? 


\section{Instructors Notes}

This is a case involving the implementation of an orientation program. Midwest Education has decided to develop an orientation program after suffering a decrease in productivity and learning of complaints from new employees. The only constraints for the case are the $\$ 30,000$ budget and the requirement for job shadowing being included in each program. Students are allowed to choose whatever combination of activities they deem important.

\section{Question 1}

Students can choose the options they prefer as long as they justify their decision. Students should focus on the strategy of each division, tailoring the orientation program to the strategy of that division. The orientation program for the Creative Development Division should focus on innovation. The orientation program for the Manufacturing Division should focus on quality. The orientation program for the Transportation, Service, and Maintenance Division should focus on cost reduction.

There are many options for the orientation program for each division. A good answer to question one would include the following activities being included in the orientation program for each division.

\begin{tabular}{|c|l|c|}
\hline \multicolumn{1}{|c|}{ Manufacturing Division } & Cost \\
\hline Days & \multicolumn{1}{|c|}{ Activity } & $\$ 1080$ \\
\hline 1 & Teamwork Seminar & $\$ 2420$ \\
\hline 3 & Quality Management Seminar and workshop & $\$ 250$ \\
\hline 1 & Games and Cases Packet- Teamwork & $\$ 275$ \\
\hline 1 & Games and Cases Packet- Diversity & $\$ 250$ \\
\hline 1 & Games and Cases Packet- Cost Reduction & $\$ 800$ \\
\hline $1 / 2$ & Video- Quality Management & $\$ 975$ \\
\hline
\end{tabular}

The length of the training portion of the orientation program is 8 days. The recommended length of job shadowing is 15 days. The total length of the orientation program for the Manufacturing Division is 23 days.

\section{Creative Development}

\begin{tabular}{|c|l|c|}
\hline Days & \multicolumn{1}{|c|}{ Activity } & Cost \\
\hline 1 & Teamwork Seminar & $\$ 1080$ \\
\hline 3 & Creative Solutions Seminar and workshop & $\$ 2140$ \\
\hline 7 & Creativity Camp & $\$ 15,000$ \\
\hline 1 & Games and Cases Packet- Teamwork & $(250)$ \\
\hline 1 & Games and Cases Packet- Thinking Outside the Box & $\$ 325$ \\
\hline 1 & Games and Cases Packet- Diversity & $(275)$ \\
\hline $1 / 2$ & Video- Thinking Outside the Box & $\$ 1000$ \\
\hline $1 / 2$ & Video- How to Be an Efficient Employee & $(975)$ \\
\hline
\end{tabular}

The length of the training portion of the orientation program is 15 days. The recommended length of job shadowing is 15 days. The total length of the orientation program for the Creative Development Division is 30 days.

Transportation, Service, and Maintenance Division

\begin{tabular}{|c|l|c|}
\hline \multicolumn{1}{|c|}{ Activity } & \multicolumn{1}{|c|}{ Cost } \\
\hline 1 & Teamwork Seminar & $\$ 1080$ \\
\hline 3 & Cost Cutting Seminar and workshop & $\$ 1840$ \\
\hline 1 & Games and Cases Packet- Teamwork & $(250)$ \\
\hline 1 & Games and Cases Packet- Diversity & $(275)$ \\
\hline 1 & Games and Cases Packet- Cost Reduction & $\$ 250$ \\
\hline $1 / 2$ & Video- How to Reduce Costs & $\$ 575$ \\
\hline $1 / 2$ & Video- How to Be an Efficient Employee & $(975)$ \\
\hline
\end{tabular}


The length of the training portion of the orientation program is 8 days. The recommended length of job shadowing is 15 days. The total length of the orientation program for the Transportation, Service, and Maintenance Division is 23 days.

The total cost of the orientation programs for the three divisions is $\$ 29,340$.

\section{Question 2}

For question two, students can answer with any length of time, however they should explain why they chose the specific length of time. Students should focus on the orientation programs lasting from two weeks to one month. While new employees are participating in an orientation program, they are not contributing to the company; this is one reason why the length of the orientation program should be limited.

\section{Question 3}

Students should answer any length of time they prefer and justify their decision. The length of time in which each new employee undergoes job shadowing should be limited as it reduces the productivity of the mentor. However, job shadowing is a useful way to teach new employees what tasks they are expected to complete and how to complete said tasks, and is a relatively inexpensive option.

\section{Question 4}

Students should come up with additional activities for the orientation program, not considering the cost of the activities. The instructor could ask students to explain which activities would be most effective for each division.

\section{Question 5}

For question five there are multiple methods for evaluating the success of training. These methods include; post measure, pre/post measure, pre/post measure with a control group, results based testing, behavior based testing, learning based testing, and reaction based testing. Student's answers should be based on the listed methods for evaluating training. The instructor could ask students to describe pros and cons of using each method. The most effective method for evaluating the success of training is the pre/post measure with a control group.

\section{AUTHOR INFORMATION}

Dr. Art Fischer is a University Professor of Management in the Department of Management and Marketing at Pittsburg State University. He is a FELLOW with the American College of Healthcare Executives, and is a retired healthcare executive. E-mail: afischer@pittstate.edu, corresponding author.

Sarah Brownback is a lifelong resident of Kansas. She currently is a senior at Pittsburg State University majoring in International Business, Management, and Marketing. She intends to enter into a career in human resource management. In June 2011 she attended a study abroad in La Rachelle, France where she studied European business practices. She plans to continue her internationalization with extensive travel throughout France. When not in school or working she enjoys kayaking, hiking and crafting. E-mail: sj_brownback@yahoo.com 
NOTES 